\title{
Socio-Cultural Adaptation of Repatriates of East Kazakhstan and Migration Attitudes of the Kazakhs of Mongolia
}

Albina Sovetovna Zhanbossinova, ${ }^{+*}$ Maxat Serikovich Karibaev, ${ }^{\dagger}$ Bakyt Zhymagazuevna Atantayeva, ${ }^{\dagger}$ Arman Ayypbekovna Kulshanova ${ }^{\ddagger}$ and Mendyganym Dzhamalbecovna Shaimerdenova ${ }^{*}$

\section{Abstract}

The article is devoted to the issues of socio-cultural adaptation of repatriates on the territory of East Kazakhstan and the analysis of the migration attitudes of the Kazakhs of Mongolia. Since Kazakhstan gained independence on 16 December 1991, the state has been implementing a state program on the return of ethnic Kazakhs to the country; this practice has spread in many states. The repatriation of ethnic Kazakhs to their historic homeland allows solving many socio-economic, demographic problems. At the same time, relocation to a historic homeland causes a new set of problems related to the adaptation of repatriates, their employment, interaction with the local population, search and self-awareness. Integration processes and strategic social programs of Kazakhstan have become the motivation for the formation of the migration interests of ethnic Kazakhs living abroad.

Keywords: Repatriates, Migration, Ethnic Kazakhs, East Kazakhstan

\footnotetext{
${ }^{\dagger}$ Sarsen Amanzholov East Kazakhstan State University

${ }^{*}$ Corresponding Author, Emails: zhanbossinovaa@bk.ru and sovetuk@rambler.ru

' Shakarim State University of Semey

${ }^{¥}$ T.K. Zhurgenov Kazakh National Academy of Arts

(C) 2019 Zhanbossinova et al. This is an Open Access article distributed under the terms of the Creative Commons Attribution License (http://creativecommons.org/licenses/by/2.0), which permits unrestricted use, distribution, and reproduction in any medium, provided the original work is properly cited.
} 


\section{Introduction}

In the history of the Kazakh people, there were a lot of tragic pages that forced a part of the population to migrate outside the ethnic territory. The mass displacement of the Kazakh population outside the country was due to political events, military conflicts, such as punitive expeditions from the times of imperial politics to suppress national liberation uprisings, including 1916, political terror and the economic policy of the Soviet state in 1920s-1930s (Bonnenfant, 2012).

Since the declaration of state independence on 16 December 1991, the Government of the Republic of Kazakhstan adopted a number of laws and policy documents on the return of the Kazakhs living overseas to their historic homeland. The practice of inviting compatriots living outside the country is a natural phenomenon in world politics. For Kazakhstan, the implementation of the state program for the return of ethnic Kazakhs is of current importance in the light of strategic tasks, such as 'Strategy2050', 'Rouhani zhanghyru' (spiritual renewal). The return of repatriates allows solving one of the acute problems of Kazakhstan related to demography.

Currently, the number of compatriots wishing to relocate from abroad is not decreasing. According to the Agency for Migration and Demography, representatives of the Kazakh diaspora live in 45 countries, accounting for onethird of the total number of representatives of the Kazakh nation, or about 4.5 million people.

Kazakhstani authors consider the social adaptation of repatriates in terms of their adaptability to new environmental conditions (Sadyrova and Amitov, 2017). In their article entitled Migration Processes in Kazakhstan and the Social Adaptation of Oralmans: Sociological Analysis conducted a sociological study of the social adaptation of ethnic repatriates in modern Kazakhstani society, identifying the factors influencing the process of successful integration of this social group in Kazakhstani society. This publication addresses the issues of language adaptation of children of repatriates in the conditions of the modern Kazakhstan education system, pointing out the difficulty of identifying these children at school (Sadyrova and Amitov, 2017). Similarly, the study of G. Mendikulova (1997) revealed issues of the historical process of emergence and formation, as well as the current state of the Kazakh diaspora, which is of the particular importance of our research. This is the first attempt in Kazakhstan historiography to comprehensively study the problem of a part of the Kazakh people living outside the territory of sovereign Kazakhstan. The book is written based on documentary sources collected in the libraries of Kazakhstan, Russia, Europe and the USA, as well as the author's personal meetings with representatives of the Kazakh diaspora and irredenta living in different countries of the world. The author believes that "the idea of repatriation should serve to strengthen the ethnic image of the Kazakhs as a whole" (Mendikulova, 1997: 79). The book says that ethnic repatriates contribute to the revival of the cultural heritage of the nation and strengthen the spiritual foundations. Compatriots living in a different ethno-social space are able to preserve some examples of national art, traditions and customs.

Diener (2005a) seemingly argued that migration flows of ethnic Kazakhs to their historic homeland are due to the formation of the independent Republic of Kazakhstan. For many of them, who heed the call of migration to their historical territory, Kazakhstan is very different from the homeland that they represented, idealised. The author pays attention to the legal and political shortcomings of the state program for the resettlement of compatriots, the analysis of state assistance, the complexity of adaptation of immigrants (Diener, 2005a). Kazakhstan indeed initiated repatriation policy, positioning the country as the homeland of the Kazakh diaspora. The author focuses on the discourse of Kazakhstan's leaders on the repatriation of their compatriots, as well as the legal and political context created to achieve their smooth 
absorption in the national society (Bonnenfant, 2012).

Isaacs and Polese (2015) similarly consider the alternative discursive Kazakh constructions of the 'Kazakh Motherland' in Mongolia and Kazakhstan, their idealisation as ancestral rootedness, and mobility as the basis of the sense of 'belonging' to the Land (Isaacs and Polese, 2015).

Nonetheless, since 1991, there has been a largescale movement of ethnic Kazakhs from Western Mongolia to Kazakhstan. This migration is influenced by economic motives, historical and cultural ties with Kazakhstan, the immigration policy of both the countries. The authors assess the local and national conditions that shape the process of making migration decisions in Western Mongolia in transitional years and highlight changes in the characteristics and directions of migration flow during this time. The authors identify three periods of migration; each is characterised by changes in the economy and national policy of Mongolia and Kazakhstan, as well as changes in communication technology and extensive social networks among potential migrants. These periods illustrate the evolution of transnational migration flows over time and their impact on national, local and individual conditions (Barcus and Werner, 2010; Diener, 2005b).

In the era of heightened globalisation and as a result of migration flows to the countries of Europe, America and Central Asia, the problem of the socio-cultural adaptation of migrants becomes urgent. Several scholars have recently undertaken studies to demonstrate the various means of socio-cultural and psychological adaptation of the migrants (students, teachers, other employees ) in different socio-cultural environment (Biserova and Shagivaleeva,2019; Fayzullina, 2019; Lashari, Kaur and AwangHashim, 2018; Taušová et al., 2019; and Tanova and Ajayi, 2016). For instance, scholars have discussed the establishment of Club of International Friendship (CIF) "UNITY" at Kazan Federal University, Kazan, Russia which serves as a platform to ease the difficulties the international students from Turkmenistan,
Uzbekistan, Iran, and Tajikistan face (both social and psychological) while trying to acclimatise at Kazan (Biserova and Shagivaleeva,2019; Fayzullina; 2019). These studies are similar to the studies conducted by scholars (Haslberger et al., 2014; Tahir, 2018; He et al., 2019) demonstrating that the strategy of separation acculturation is more conducive to psychological adaptation than the strategy of integration. Similarly, Konanahalli et al. (2014) studied the implications of the cross-cultural adaptation of British expatriates and concluded that lacking foresight and appropriate strategies; organisations can hinder the effectiveness of the assignment by producing frustrated, disillusioned, discontented expatriate staff. Another research area concerns targeted migration organised by the state for certain categories of its citizens in order to enhance their professional career (Ho et al., 2018).

The lack of direct scientific developments on the proposed problem has triggered our research, which aims at analysing the migratory attitudes of ethnic Kazakhs in the context of a different ethnic environment, on the one hand, and the problem of their socio-cultural adaptation in the conditions of the Kazakhstan community, on the other hand. This, undoubtedly, actualises the proposed problems and will allow revealing their specificity in the conditions of a single region (East Kazakhstan). The structure of the study conventionally consists of theoretical dimensions, -methodological issues and the research findings. The former is the analysis of the research degree of the problem, understanding of its main trends and the development of the authors' own scientific strategy. The latter reflects the results from the field identifying the attitudes of ethnic Kazakhs living mainly in Mongolia and the main problems of their social adaptation in the Republic of Kazakhstan. The next section discusses the issues linked to the methodology.

\section{Methodological Framework}

The interdisciplinary approach is the methodological basis for studying the history of the problem of ethnic repatriates, since repatriation - repatriates are considered as one 
of the types of migration, and are mainly studied in subjects - history, economics, sociology, and psychology. Russian historians - L. Repina (2011), I. Savelieva (2006) laid the theoretical and methodological foundations of interdisciplinary communications.

The methodological pluralism proposed by the New Historical Science expands the possibilities of sociological concepts for a more detailed study of everyday life in the context of sociocultural adaptation.

T. Parsons (2002) uses standards of adaptive behaviour with the motivation of ' $\mathrm{l}$ ' or 'Collective'. In particular, the structuralfunctional analysis of T. Parsons, where the activity within the society is a response to the demands of the society itself, that is, a new sociocultural environment of repatriates causes new forms of social interaction (Parsons, 2002).

From the perspective of interdisciplinary research and updating the format of the terminology used, the authors identified the following concepts: 'repatriation' - return to their homeland, 'repatriates' -citizens returning to their historic homeland, which are used in generally accepted repatriation concepts.

The article is based on general scientific methods: analysis, synthesis, deduction, induction, statistical method; special historical methods; scientific methods at the intersection of interdisciplinary approaches, including the method of oral questioning. The historical problems of everyday life and the processes of adaptation are determined by the methods of oral history, as well as the methods of the sociological survey, which allows to fully explore the social and cultural life of repatriates through their everyday experience.

\section{Results and Discussions}

At the II World Kurultai of the Kazakhs, President N.A. Nazarbayev said: "There is only one Kazakh nation in the world, and its national identity, traditions and customs are inherent in all Kazakhs, its magnificent spiritual treasures are an indivisible commonwealth" (Nazarbayev, 1997: 1). Kazakhstan, taking into account international experience, provides all possible support to compatriots in moving to their historic homeland (Nazarbayev, 1997).

It should be noted that at present, there is a unique problem in the study of complex problems of repatriates. It refers to the difficulty of adapting to the new social environment, due to the different levels of manifestation of national self-awareness of compatriots from the countries of near and far abroad, as well as changes in the ethnic worldview, which is explained by their adaptation to other social concepts, attitudes, habits and opportunities for many years.

The traditions, customs, language and culture, religion and mentality of the compatriots living on the territory of other states are influenced by the social environment, religious trends, and economic structure of the country of residence (Nurmakov, 2005). A special feature in the adaptation of repatriates to the social environment is the significant difference in everyday life, customs, and culture with the region where they lived before relocation. Citizens arriving from different countries have their cultural characteristics, and social stereotypes since the political system of their native country have a direct impact on their consciousness.

Analysing the socio-cultural characteristics of adaptation to the local environment of ethnic repatriates from China, Mongolia and Uzbekistan, who constitute the central part of the immigrants in the East Kazakhstan region, we can draw the following conclusions:

The Kazakhs who migrated from China pay more attention to the peculiarities of Eastern culture (Chinese, Uygur, and Arabic) and Muslim traditions than to Western culture. They continued the tradition of animal husbandry, retained such qualities as honouring oral and written literature, respect for the arts (Burkhanov and Chen, 2016). However, in the social sphere, many phenomena lead to a lag in ethnic competition, including some moments of rejection of Chinese Kazakhs by local Kazakhs in their historic homeland (Sadovskaya, 2007; He, An and Berry, 2019). 
Nevertheless, confidence in the future is gradually increasing in the national identity of the Kazakhs from China, but it should be noted that at the present stage there are problems between the two countries that need to be solved at the international level. One of them is a low level of information, limited cultural communication. In this regard, it should be noted that repatriates from China and Mongolia retained the economic structure, peculiarities of the customary lifestyle.

The second largest group of compatriots resettled in the region (from outside the Commonwealth of Independent States) are the Kazakhs from Mongolia. In general, about 150,000 Mongolian Kazakhs resettled in Kazakhstan; they account for $40 \%$ of all returnees in the East Kazakhstan region. Now the key question that arises is, what the peculiarities are in the mentality of citizens who have migrated from this country?

The Kazakhs in Mongolia, one of the most significant minorities in the country, about $6 \%$ of the total population, make up the overwhelming majority in the area of their compact residence -about 90\% (Data from a sociological survey conducted in the Bayan-Olgei aimak of the Republic of Mongolia, 2018). Therefore, the Kazakh language, customs and traditions are well preserved. However, Islam, because of the atheistic attitude towards religion, was preserved only at the household level. Due to the lack of industry in this region, the population has maintained a tendency to engage in animal husbandry.

In the Kazakh school, lessons in Mongolian are more prevalent than lessons in Kazakh. However, it should be noted that young people do not confuse the Mongolian language with the Kazakh language. This indicates that it is in the nature of the Kazakh people to learn various languages.

At present, the Kazakhs of Mongolia are fully provided with information about political and cultural events taking place in Kazakhstan, since they have access to the free viewing of Kazakhstan TV channels.

In the East Kazakhstan region, in terms of the number of repatriates are ethnic Kazakhs from Uzbekistan, constituting $5 \%$ of the number of repatriates. If we talk about the identity of compatriots who migrated from this state, then it can be noted that the Kazakhs there know their national history, traditions, customs, language, religion and, basically, have preserved these spiritual structures well, but due to social difficulties in the society, the Kazakhs changed their nationality to Uzbeks. Of course, the way of life, culture and traditions of the local people Uzbeks - influenced other ethnic groups, which is a natural phenomenon (Fumagalli, 2007).

The mentality of the Kazakhs from Turkey is completely different. They are close to Western culture, quickly adapt to the social environment, are more inclined to integrate, have a high level of ethnic consciousness (Atantayeva et al., 2016). However, in the eastern region of Kazakhstan there is a very low percentage of repatriates from this state.

In this regard, it should be noted that scientific research of this issue encounters certain difficulties, and this process requires the support of the state.

In order to study this problem in depth, a survey was conducted among repatriates in the East Kazakhstan region, and they were asked the following question: "Did you notice the similarity of the socio-cultural situation in Kazakhstan with the previous region of residence?"

The following answers were received (Figure 1) $-60 \%$ of the respondents indicated that there is a difference which is not comparable; $23 \%$ reported that there is similarity in lifestyle and traditions; while only $15 \%$ had reflected on very few similarities between the two cultures. 


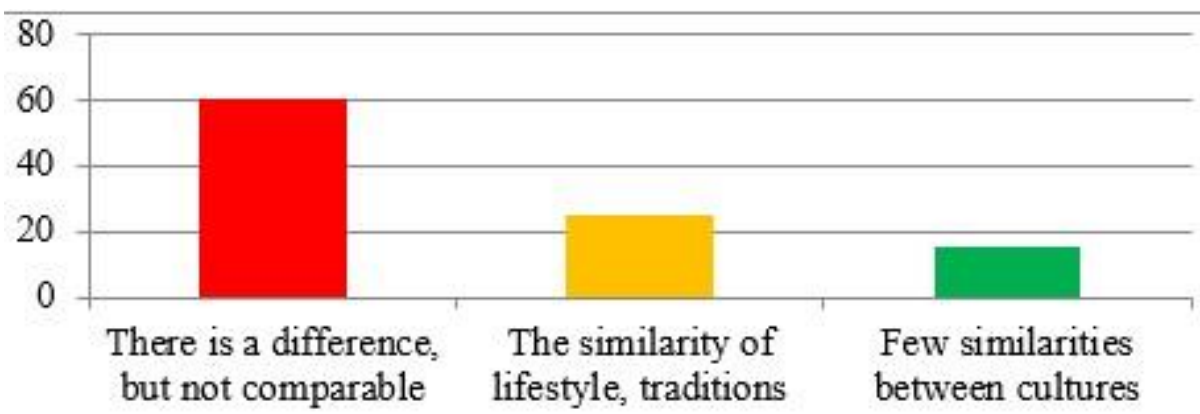

Figure 1: The Similarity of the Socio-Cultural Situation in Kazakhstan with the Previous Region of Residence

Source: Compiled by the Authors

Problems of language and cultural integration also complicate the process of adaptation of repatriates. The big problem that prevents compatriots from far and near abroad to integrate into the local environment is the Kazakh alphabet.

Currently, the Kazakhs of the world do not have any differences in colloquial speech, but a situation has arisen where Kazakhs living in different countries do not understand each other's written language. Kazakhs in different countries use three types of the Kazakh alphabet: Cyrillic, Latin and Arabic. For example, Kazakhs who arrived from Uzbekistan and Turkmenistan, and Kazakhs living in Europe, learned to read and write using Latin alphabets. The migrants from China use the ancient Kazakh script based on the Arabic alphabet. The Kazakhs of Mongolia, Russia and the CIS countries use the Cyrillic alphabets. Therefore, immigrants from these countries do not have particular difficulties in spelling (Nysanbayev, 2005).

This difference causes difficulties for relatives who returned to their historical homeland, especially when they try to get a secondary and higher education. To overcome these difficulties, the state creates all conditions in Kazakhstan: all over the regions, there are special centres for oralmans to study the language and writing of the local population; young people who want to enrol in higher education institutions do training courses for a year or a year and a half; they are provided with housing, free lectures (Lashari, Kaur and Awang-Hashim, 2018).
One of the processes that facilitate adaptation is the creation of conditions for each of the foreign compatriots to receive education in secondary and higher educational institutions. This, of course, is a great opportunity offered by the state. However, the diplomas obtained do not always guarantee employment in the host countries (Mongolia, China, etc.). Modern graduates of Kazakhstan have several problems that prevent them from finding work in their speciality after receiving a diploma, and, as a result, they are forced to work in other areas (Biserova and Shagivaleeva, 2019). In this matter, it would be possible to achieve a positive result, if the state takes measures on the mandatory employment of graduates.

Persons of Kazakh nationality, arriving from the CIS countries, are the most adapted category of immigrants. The main reason is that in these countries in Soviet times, they spoke a common language and had a common Cyrillic writing system.

The difficulty of adaptation of repatriates from China, Mongolia, and Turkey is aggravated by the difference in mentality, language barriers, and differences in the conditions of social life (Barcus and Werner, 2010).

To solve a number of problems of repatriates, Kazakhstan, which does not have much practice in holding such events, should carefully study the rich experience of the international community, including countries such as Germany and Russia, actively pursuing the policy of returning their compatriots (Study of the status of oralmans in Kazakhstan, 2006). 
One of the main reasons for the return of ethnic Kazakhs to their historic homeland is their desire to preserve the Kazakh identity, language, culture and traditions of their people. It is necessary to create an effective system to ensure the continuity of generations.

A complex social phenomenon that requires excellent assistance from the state is the problem of ethnic integration and adaptation of repatriates to new conditions after the relocation. Living for many years in a different ethnic environment led to many features in their sociocultural position. Proceeding from this, adaptation is an active human activity in adjusting to a new environment and accepting a new social reality (Fayzullina, 2019; Fialkova and Yelenevskaya, 2007; Haslberger et al., 2014; Tahir, 2018; He et al., 2019).

The political, socio-cultural structure of our compatriots, who lived for years in a different ethnic and cultural environment, led to changes in traditional culture, language and behaviour (Atantayeva, Mamyrbekov and Ospanova, 2016).

Table 1: The Process of Adaptation of Repatriates to the Social Environment
The first group are teenagers. They quickly adapt to the social environment, much faster
than parents adopt cultural norms and values that correspond to the new environment.
The second group is the youth. Their adaptation is more complicated than in
adolescents. The social environment changes. The difference in the form of clothing,
behaviour, language structure can cause many difficulties in adaptation.
The third group are middle-aged oralmans. Compared to young people, it is more
difficult for them to integrate into the socio-cultural environment, to maintain close
contacts with the society, to learn the language and writing of the local population.
The fourth group are senior citizens. For them, changing the cultural environment is
critical. For repatriates of this age group, it is beneficial to live in the countryside, whose
inhabitants adhere to the Kazakh traditions, where they do not need to adapt to other
cultural conditions.
Note: The Authors compiled the table on the basis of data from 'Promoting the socio-economic
integration of oralmans' UNDP / UNV project (United Nations Development Program / United
Nations Volunteers Program, 2009)

As noted in Table 1, the age characteristics of repatriated citizens play an important role in adapting to the socio-cultural environment. Adolescents more quickly adapt to the new environment and actively perceive the main
Therefore, the adaptation of compatriots who returned to their homeland to everyday life and cultural life in their historic homeland requires considerable time, tolerance, and the implementation of many socio-cultural measures by the state. The problem of ethnic integration is a serious socio-psychological phenomenon (Kalshabayeva, 2011). The support of compatriots from the local population is essential here. In this regard, there is a need for state social and demographic policy.

In the study of the adaptation process, depending on the age characteristics of repatriates, four groups can be distinguished: adolescents, young people, middle-aged people and the elderly.

Individual and group factors reflect achievements in adaptation to the social environment. There are individual factors (age, gender, education) and personal characteristics, life competence, communication skills.

Table 1 shows the age characteristics of repatriates in adaptation to the social environment. aspects of social reality. For young people, the adaptation process is slower; their relations with the local population are slowing down; they try to communicate mainly with each other. 
For middle-aged people, integration into society, establishing contacts is one of the most complicated processes. Changing the cultural environment for this age group is a difficult challenge.

For older people, changes in the sociocultural environment are becoming difficult trials, they are not able to adapt to a different social environment, and there is no need to adjust to the social reality, cultural environment, and the modern view of Kazakhstan's society - culture and language, in particular, Russian, if they do not have any internal needs. In such a situation, elderly people may experience devaluation of their personality, a decrease in the sense of ownership, and a loss of influence on the younger generation (Nurmuratov, 2005).

To eliminate these problems, special plans have been developed, and the state allocates a significant portion of funds for the adaptation of our compatriots from other countries. In each region, there are adaptation centres for repatriates.
Among the difficulties faced by oralmans in the process of social adaptation, the problem of cultural, psychological and mental compatibility with local residents is particularly important. Unfortunately, today, there is sometimes a situation of rejection by the local population to the newly arrived Kazakhs, and this is a serious psychological phenomenon for the oralmans.

For a person who comes from a different social environment, another state, any action can have a severe impact on his/her spiritual world. For example, for them, it is imperative that they receive a friendly welcome and are given exhaustive information about the issues of receiving documents.

One of the objectives of a sociological study conducted among returnees of the East Kazakhstan region was to identify problems after returning to their historic homeland. The repatriates were asked to answer the question: What difficulties have you encountered during the period of adaptation to the new culture?

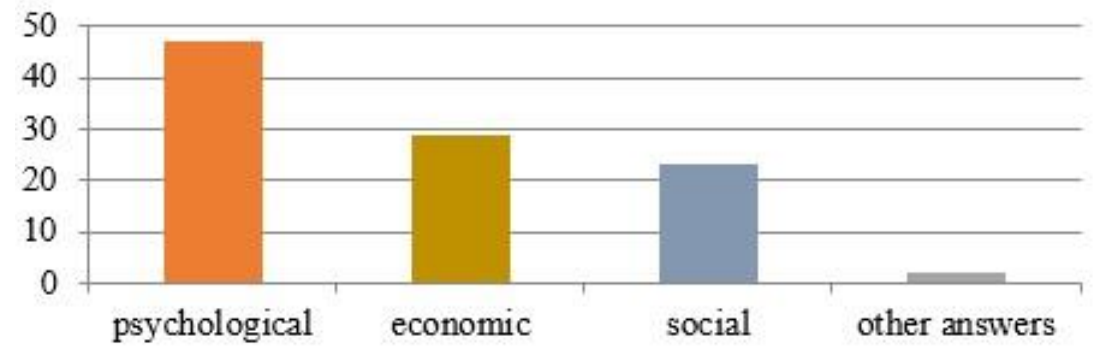

Figure 2: Difficulties of the period of adaptation to the new culture Source: Compiled by the Authors

It is apparent from Figure 2 that $47 \%$ of the respondents noted psychological factor; $28 \%$ indicated economic problems, $23 \%$ spoke about social problems, and $2 \%$ gave a different answer. The survey showed that the majority of the respondents attributed problems in adaptation not with their economic or social status, but with the ambiguous attitude of the local population towards them (Data of a Sociological Survey $\mathrm{c}=$ Conducted in the East Kazakhstan Region, 2018).

As a result, repatriates have established a kind of social distance with the local population; they live compactly, in isolation, and their circle of contacts is limited mainly to relatives. Of course, the adaptation process will go at a rapid pace only if it is integrated into society, and not in the circuit and isolation. Also, it is necessary to realise that constructive communication with citizens arriving from abroad should be based on a common language, culture, spirituality, and religious foundations.

The compatriots who have migrated from abroad have substantial differences in language and culture, depending on the country of residence. The social environment can change a person; particularly, the acute 
problem of Kazakh repatriates is language assimilation.

Repatriates take a long time to gain a foothold in a new place, to join a new culture and society. Nonetheless, the consolidation of repatriated families in the same territory has begun. For example, in the East-Kazakhstan region, residential communities, schools and kindergartens for Oralmans have been constructed in Kurchatov, Vostok settlement, Novo-Yavlenka.

However, in the course of the research, it turned out that small settlement on one territory slows down the adaptation process. Socio-psychological adaptation of the compatriots is a big problem. The lifestyle of immigrants is changing. Even changing home furnishings have positive or negative consequences for people. Therefore, immigration from abroad, integration into another environment is one of the problematic processes. It needs special attention, a particular help to the repatriates in adapting to the environment (Kalshabayeva, 2011).

Based on this, it became necessary to create special 'Oralman Centres' to adapt to the social environment after the repatriates arrived in the country. Special centres for immigrants began their work in regional centres. The state required the creation of special 'adaptation centres'. Upon arrival in Kazakhstan, the oralmans should receive citizenship and quota, and the state resolves this issue only through the migration committee and the department of employment and social programs.

State bodies do not organise free courses for oralmans. In this connection, special programs began to be developed and implemented to solve many problems of adaptation and integration of oralmans through the training of the Russian language, computer skills and studying the laws of the Republic of Kazakhstan (Abildina, 2017).

In the republic, adaptation centres are now functioning, and the main goal of the Nurly Kosh program is to find a simplified way of adaptation of oralmans to society. Based on this, in 2009, in the city of Semey, within the framework of the UN Development Program, the Centre for the Promotion of Social and Economic Integration of Oralmans was established (Promotion of the socio-economic integration of oralmans, 2011).

The main work of the centre is to provide services for adaptation of oralmans to the public, their professional training and retraining. In the East Kazakhstan region in the period from 2009 to 2016, the Adaptation Centre gave a great result of work on social adaptation, maintaining close cooperation with repatriates.

However, every year, there is a risk of slowing down this process. Experience has shown that adaptation to the social environment on a social, economic, psychological, legal basis requires the constant implementation of activities within a specific program.

Currently, citizens who have returned to their historical homeland are faced with problems of a socio-economic, socio-cultural, and civil law nature (Diener, 2005b). To solve these problems, the state has approved and implements special regulatory and state programs. Based on this, one of the urgent problems is the study and assessment of the migration attitudes of the Kazakhs of Mongolia.

The authors conducted a study among the Kazakhs of Mongolia, leading in the total number of immigrants to Kazakhstan, and, in particular, in the East Kazakhstan region, in Bayan-Ol'gei aimag, where they make up $90 \%$ of the population (more than 102 thousand Kazakhs live there).

In general, over 257 thousand Kazakhs live in Mongolia, of which about 150 thousand moved to Kazakhstan. However, unfortunately, about 10,000 ethnic Kazakhs could not adapt to local conditions and returned to Mongolia. Now their opinion on Kazakhstan may affect the position of those who are thinking of resettlement to their historic homeland. In the course of the study, a face-to-face survey was conducted among Kazakhs living in the city of Bayan-Ol'gey, to identify the migratory mood 
of Kazakhs in Mongolia and attitudes towards Kazakhstan.

In the first part of the questionnaire, it was planned to receive information on the sociodemographic situation and the degree of kinship of repatriates.

One hundred respondents took part in the survey. From the gender perspective, $49 \%$ of men, $51 \%$ of women took part in it. Of these, $53 \%$ are young people (coverage $14-29$ years old), $45 \%$ are middle-aged citizens (coverage
$29-59$ years old), the remaining $2 \%$ are citizens over 60 years old.

The findings showed that the majority of respondents understand the Kazakh language (91 people) and the Mongolian language (52 people), speak these languages and use them daily. In addition, 15 respondents speak Russian, and three respondents speak English (Figure 3 ). In general, $45 \%$ of respondents have secondary education, $37 \%$ - higher education and $18 \%$ - vocational education (Figure 4 ).

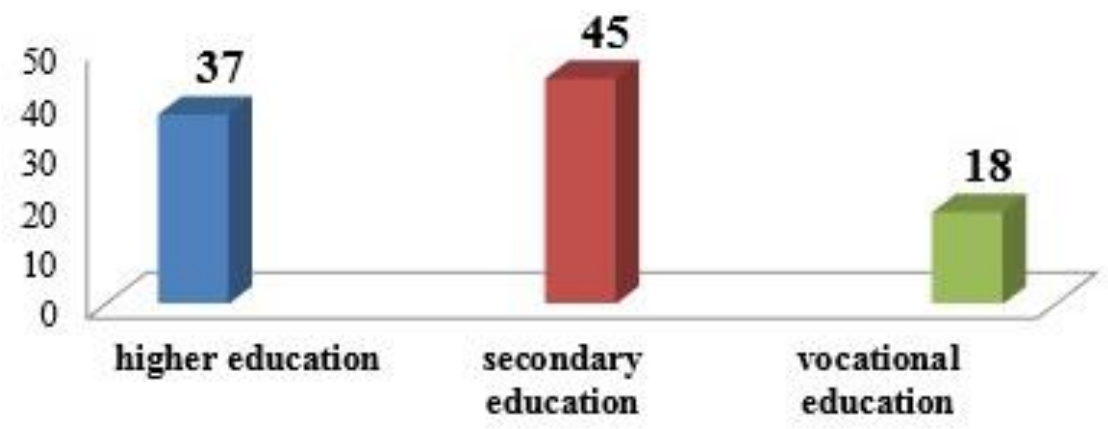

Figure 3: Information on the Educational Level of the Respondents Source: Compiled by the Authors

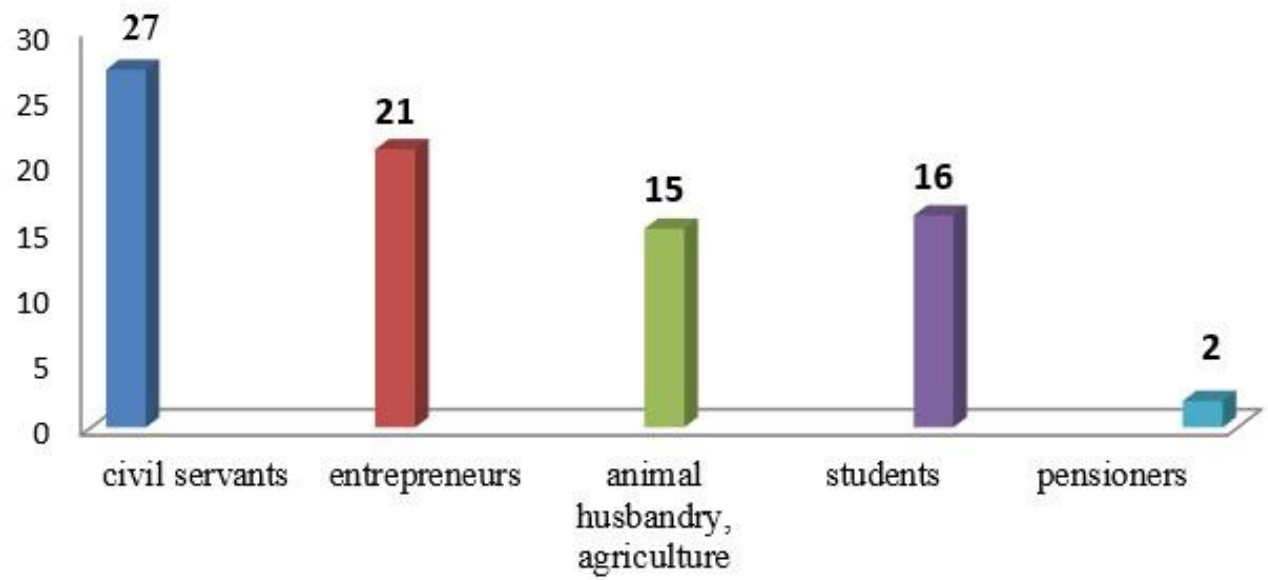

Figure 4: Field of Activity of Respondents Source: Compiled by the Authors

Depending on the level of knowledge, the scope of activity in which respondents are currently engaged was defined.

When asked how long they lived in Mongolia, 43 respondents responded that they were born in Mongolia (1-70 years)"; 30 respondents said that their ancestors had lived in Mongolia (50-
90 years)", but only eight respondents indicated that they are - immigrants from Kazakhstan, but 20 respondents consider Mongolia to be their historical homeland.

At the same time, in the course of obtaining information on family relations in Kazakhstan, only four respondents noted that they have no 
relatives, nine respondents have relatives among local residents, 49 respondents have relatives living in Kazakhstan for $10-20$ years, 38 respondents noted that their relatives live in Kazakhstan for the last 5-10 years.

In the next section of the questionnaire, information was received about the general

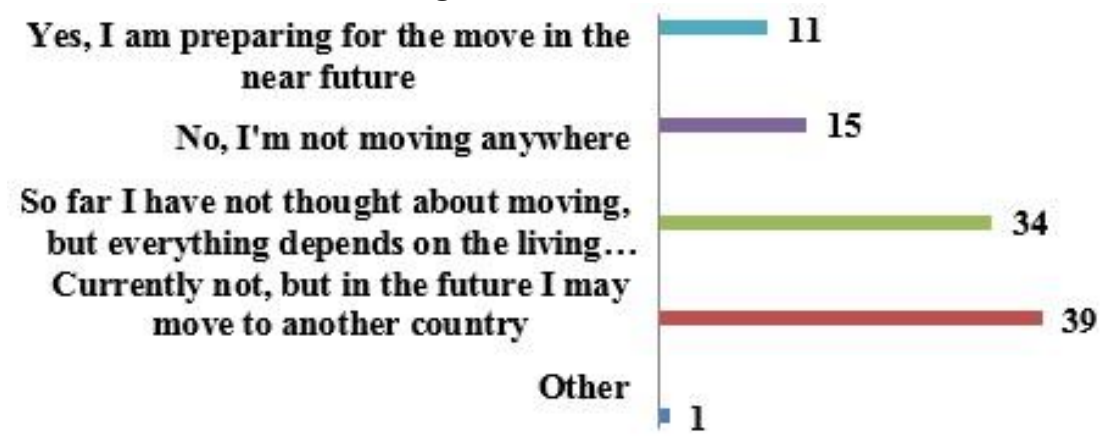

Figure 5: Information About the Mood of the Respondents About Future Plans Source: Compiled by the Authors

According to the survey results (Figure 5), it is obvious that respondents do not consider Kazakhstan as a permanent place of residence. Of the 100 respondents, 84 have considered the possibility of relocation. Of these, 11 respondents reported that they are ready to move shortly. Only 15 respondents plan to reside permanently in Mongolia. Along with the question of what influenced the decision to move to Kazakhstan, a question was also asked about the reasons why they left Kazakhstan. The respondents indicated the following reasons:

- the desire to return to their historic homeland -34

- moving to a country with a higher living standard - 33

- an unfair solution of language problem 3

- the desire to unite with family, relatives $-13$

- lack of developmental prospects for children -5

- deterioration of interethnic relations -2

- the hope of providing benefits in their historic homeland -2

- all ethnic groups must live in their historic homeland -5 mood of the respondents and plans for the future. The following question was asked for this: Do you want to change your place of residence in the near future? Do you and your family want to move to your historical homeland in Kazakhstan?

9

- wish to be a full-fledged citizen and live in his/her own country -3

The analysis of the data obtained showed that they are mainly resettled in order to return to their historic homeland and improve their living standards.

Also, the citizens of Mongolia were asked to answer the question: In your opinion, what difficulties would you encounter upon arrival in Kazakhstan?

The first main problem is housing - 47 respondents.

The second problem is the lack of access to healthcare services - 17 respondents.

The third problem is the difficult economic situation and employment - 14 respondents.

Further:

Eight respondents noted difficulties in obtaining citizenship;

Five respondents - the problem of adaptation to local conditions;

Four respondents - they do not speak the Russian language;

Three respondents - problems in finding a common language with the local population; 
One respondent - inaccessibility of education for children, lack of future for family and children;

Nine respondents - found it difficult to answer the question.

During the survey, participants expressed their views on the relocation of oralmans in Kazakhstan:

- Repatriates must be placed on the territory of Kazakhstan equally with the local population -30

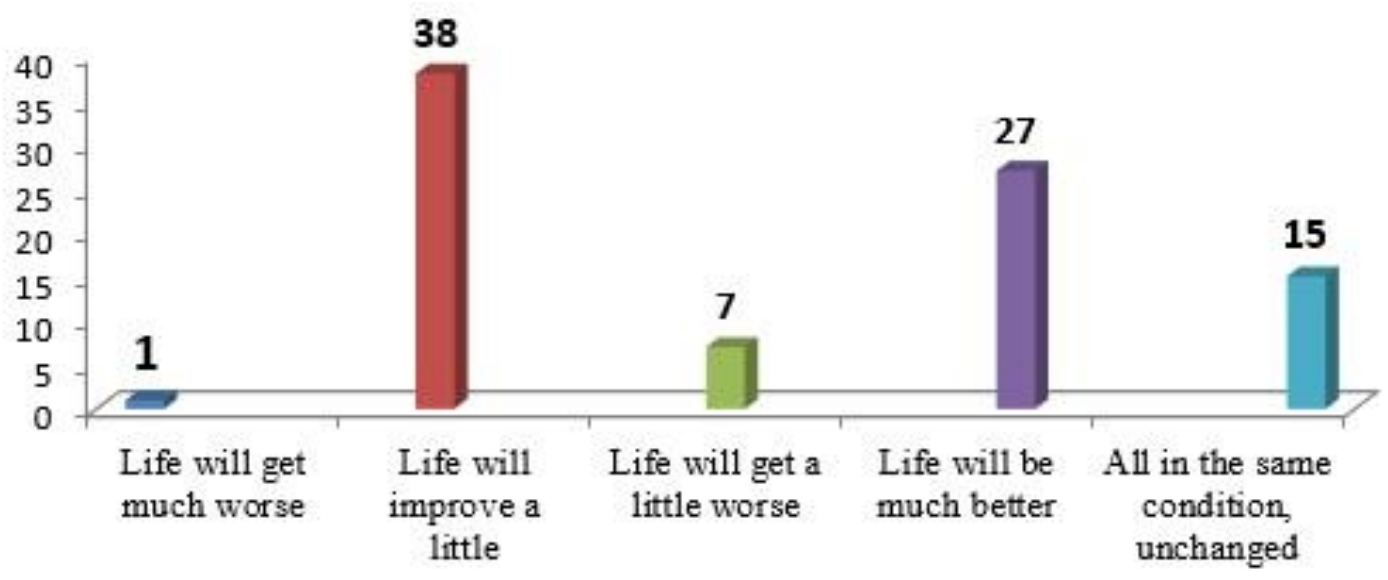

Figure 6: Respondents' Expectations from the Homeland Source: Compiled by the Authors
The overwhelming majority of respondents (65) stated that their lives would change significantly from the moment they arrive in Kazakhstan (Figure 6). Fifteen respondents said that their life would not change; it would remain in the same condition. Eight respondents informed that life would get "a little" or "much" worse.

The next question was If you came to Kazakhstan, what would you do and how could you contribute to the development of the country? The answers were as follows:

- I will spread the Kazakh language; participate in public life -34 respondents;

- I will be engaged in agriculture, cattle breeding - 25 respondents;

- I would contribute to the cultural sphere - 20 respondents;

- I will be engaged in crafts, making national products -18 respondents.
- Repatriates must be accommodated in the city - 20

- Living in other areas, away from residents - 15

- Local governments should be engaged in the placement of oralmans - 11

- The repatriates themselves must choose the place of residence - 10 .

Then the respondents answered the question: What changes might occur after arriving in Kazakhstan? respondents were identified in relation to Kazakhstan. To this purpose, they were asked, "What problems should the state solve to speed up the adaptation of oralmans in Kazakhstan?"

According to the results of the survey, the central question of concern is "simplification of the procedure for obtaining citizenship" (44), "providing employment" and "solving housing problems" indicated by 24 and 23 respondents (Figure 7). Six people indicated "the development of small and medium business", five people noted "creating conditions for practising agriculture". Two respondents raised the issue of "retraining and vocational training", one respondent identified the question of "resettlement in regions with suitable natural and climatic conditions". 


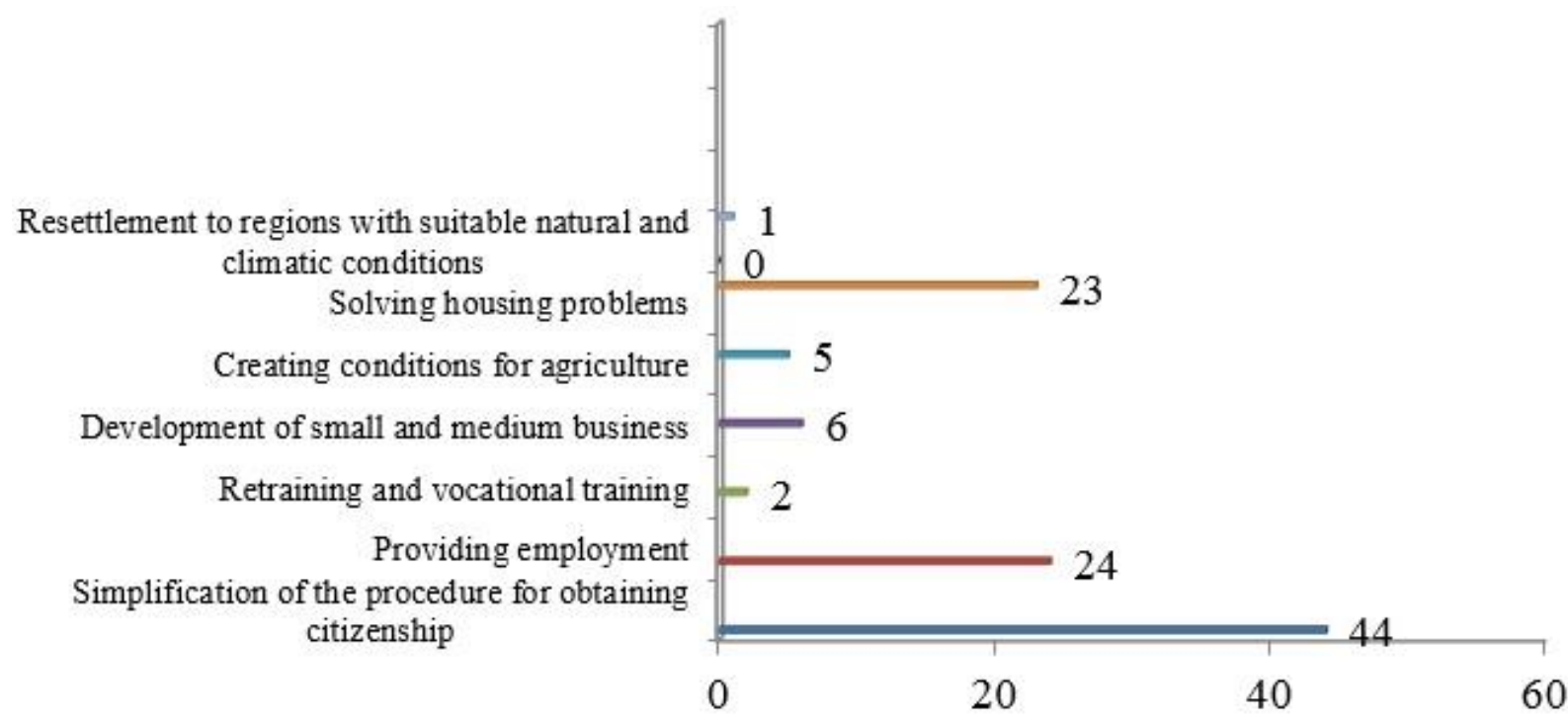

Figure 7: Objectives of the State Program on an Adaptation of Immigrants Source: Compiled by the Authors

We adhere to the definition of "patriot" as one, who loves his/her Motherland, is devoted to his/her people, ready for sacrifices and exploits in the interests of the homeland (Primoratz, 2017). Patriotism begins with respect for the family, native land, nature, and the country. A true patriot can only be one who loves his/her people, the land. In order to find out how citizens who are moving to their historic homeland

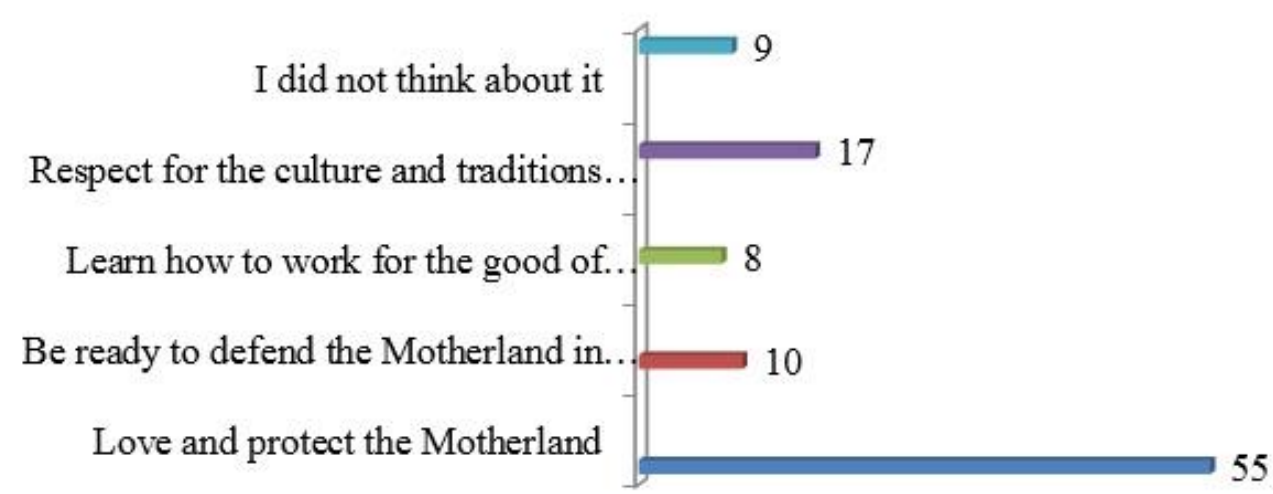

understand patriotism and what it means for them to be a patriot of Kazakhstan, the author conducted a sociological survey among repatriates.

Answers of respondents according to the results of a sociological survey were as follows (Figure 8):

Figure 8: Understanding Patriotism by Immigrants Source: Compiled by the Authors

Survey participants mainly responded within the above definition. Fifty-five respondents believe that the patriot loves his homeland and protects it, and also serves his/her country and people. Only nine respondents did not think about this question.

Taking into account the different opinions on how to name the citizens who returned to the country, one of the tasks of the sociological survey was to identify attitudes to this term from the Kazakhs living abroad.

In the last question of the questionnaire, respondents were asked the question: How would you suggest changing the term "oralman" used in relation to citizens returning to Kazakhstan? The term "Oralman" was 
supported only by nine respondents; 31 respondent suggested naming "Compatriots", 37 - "Relatives", 27 - "Kindred". Consequently, there is no single alternative to the word "Oralman"; the opinions of the respondents were divided. Further study of this issue and the development of specific proposals in the future is necessary (Data from a sociological survey conducted in the Bayan-Olgei aimak of the Republic of Mongolia, 2018).

Problems with employment, provision of housing, acquisition of citizenship worry the immigrants who arrived in their historic homeland. Due to the complexity of the implementation of these necessary conditions, repatriates hardly adapt to the conditions in modern Kazakhstan. On the part of the state, particular work has been done on the employment of oralmans.

Since the majority of oralmans came from rural areas, they were allocated funds and equipment to create agricultural enterprises and farms. A microcredit program is being implemented.

In order to simplify the process of adaptation of oralmans, several state measures are being implemented. Kazakh families who have returned home under the immigration quota are provided with housing. Those who arrive outside the quota and build their own housing, receive financial assistance from the Office of Migration and Demography, if possible. The state has taken care of those who cannot provide for themselves and the family and has all the supporting documents on this matter. The priority allocation of housing, the provision of loans to immigrants referred to in the Housing Code. However, such measures are taken slowly.

Particular attention was paid to the study of national consciousness levels, complex changes in the ethnic worldview of compatriots living in the Middle and Far foreign countries. Therefore, the process of adaptation and ethnic integration of repatriates in the new social environment, the establishment of contacts with the local population is one of the most complexes in the socio-psychological terms.
The proposed topic of the article is not limited to the framework of sociocultural adaptation and migration of repatriates. The problem field of the history of repatriates is actively investigated and discussed in the scientific space in the focus of analysis of cause-effect relationships, both new and Soviet history, and the history of the Republic of Kazakhstan (Bokayev et al., 2012; Diener, 2005a; 2005b).

A characteristic feature of the authors is the format and structure of the assessment of ethnic Kazakhs repatriation state policy, understanding of the need to create conditions for successful adaptation of repatriates.

Domestic and foreign authors are unanimous in one thing that the migratory moods of ethnic Kazakhs living outside the Motherland are intensified as the social conditions for their reception on the territory of Kazakhstan improve (Abildina, 2017; Isaacs and Polese, 2015; Nurmakov, 2005).

\section{Conclusion}

In the context of globalisation and social transformations, migration flows have become an integral part of humanity. Migration as a change in the territory of residence and adaptation as an adjustment to new conditions are interacting with structural components. The majority of immigrants to the East Kazakhstan region are ethnic repatriates from China, Mongolia and Uzbekistan.

The country from which ethnic Kazakhs migrated while maintaining the traditional mentality imposes on them the imprint of a different ethnic environment, which complicates the process of their identification in their historic homeland.

Integration processes and strategic social programs of Kazakhstan serve as a motivational message for ethnic Kazakhs living abroad. In our opinion, the Nurly Kosh state program, which has been in operation since 2008 , has been the bifurcation point of immigrants' attitudes, which envisages their rational settlement and employment, socialisation. The program's goal is to accept and settle ethnic Kazakhs arriving from abroad. The strategy provides for the definition 
of three types of labour migrants who will enjoy differentiated standards of employment and labour activity.

Despite state support, repatriates experience certain difficulties, living in a completely new, "alien" regional environment, which is especially applicable to the sociocultural space of East Kazakhstan. Ethnic Kazakhs need an extended period for adaptation. For this purpose, a set of measures was implemented to consolidate repatriated families on the same territory, to create special settlements. Living conditions, however, cannot solve all aspects of adaptation; repatriates need socio-psychological assistance, for which special "adaptation centres" have been created.

\section{References}

Abildina, G. S. (2017). Socio-cultural and linguistic adaptation of children of repatriates in the conditions of modern Kazakhstan. Actual problems of adaptation and integration of repatriates: collection of materials of the international scientific-practical conference (pp. 5-12). Astana: Publishing House of KazServisePrint LTD LLP.

Atantayeva, B.Zh., A. M. Mamyrbekov, A. K. Ospanova. (2016). The history of repatriation in East Kazakhstan (pp. 105). Semey.

Barcus, H., C. Werner. (2010). The Kazakhs of Western Mongolia: transnational migration from 1990-2008. Asian Ethnicity 11(2): 209-228.

Biserova, G., \& Shagivaleeva, G. (2019). SocioPsychological Adaptation of International Students to Learning and Professional Activities. Space and Culture, India, 6(5), 99-114.

Bokayev, B., Zharkynbekova, S., Nurseitova, K., Bokayeva, A., Akzhigitova, A., \& Nurgalieva, S. (2012). Ethnolinguistic identification and adaptation of repatriates in polycultural Kazakhstan. Journal of Language, Identity \& Education, 11(5), 333-343.

Bonnenfant, I. K. (2012). Constructing the homeland: Kazakhstan's discourse and policies surrounding its ethnic return-migration policy. Central Asian Survey, 31(1): 31-44.
Burkhanov, A., \& Chen, Y. W. (2016). Kazakh perspective on China, the Chinese, and Chinese migration. Ethnic and Racial Studies, 39(12), 2129-2148.

Data from a sociological survey conducted in the Bayan-Olgei aimak of the Republic of Mongolia. 2018.

Data of a sociological survey conducted in the East Kazakhstan region. 2018.

Diener, A. C. (2005a). Kazakhstan's Kin State Diaspora: Settlement Planning and the Oralman Dilemma. Europe-Asia Studies, 57(2): 327-348.

Diener, A. C. (2005b). Problematic integration of Mongolian-Kazakh return migrants in Kazakhstan. Eurasian Geography and Economics, 46(6), 465-478.

Fayzullina, O. (2019). Ways of International Students' Adaptation: Club of International Friendship. Space and Culture, India, 6(5), 87-98.

Fialkova, L., M. Yelenevskaya. (2007). Ex-Soviets in Israel: From personal narratives to a group portrait (pp. 1-373). Ex-Soviets in Israel: From Personal Narratives to a Group Portrait.

Fumagalli, M. (2007). Ethnicity, state formation and foreign policy: Uzbekistan and 'Uzbeks abroad'. Central Asian Survey, 26(1), 105-122.

Haslberger, A., C. Brewster, T. Hippler. (2014). Managing performance abroad: A new model for understanding expatriate adjustment Managing Performance Abroad: A New Model for Understanding Expatriate Adjustment (pp. 1198).

He, B., R. An, J. Berry. (2019). Psychological adjustment and social capital: a qualitative investigation of Chinese expatriates. Cross Cultural and Strategic Management.

Ho, N., P. Seet, J. Jones, H. Hoang. (2018). Managing the Re-Entry Process of Returnee Government Scholars in an Emerging Transition Economy - An Embeddedness Perspective. Australian Journal of Public Administration, 77 (2): 154-171.

Isaacs, R., A. Polese. (2015). Between "imagined" and "real" nation-building: identities and 
nationhood in post-Soviet Central Asia. Nationalities Papers, 43(3): 371-382.

Kalshabayeva, B. K. (2011). Problems of adaptation of compatriots (repatriates) to local conditions. Bulletin of Kazakh State University. Historical series, 4(63): 113.

Konanahalli, A., L. Oyedele, J. Spillane, M. Marinelli. (2014). The outcomes of cross-cultural adjustment: A case of British expatriates working on international architectural, engineering and construction assignments. Proceedings 30th Annual Association of Researchers in Construction Management Conference (pp. 27928). ARCOM.

Lashari, S., A. Kaur, R. Awang-Hashim. (2018). Home away from home - The role of social support for international students' adjustment. Malaysian Journal of Learning and Instruction, 15(2): 33-54.

Mendikulova, G. (1997). Historical destinies of the Kazakh diaspora: origin and development (pp. 264). Almaty: Glym.

Nazarbayev, N. A. (1997). Kazakhstan 2030. Almaty.

Nurmakov, S. E. (2005). Features of consciousness and mentality of foreign Kazakhs. The Kazakh diaspora: present and future (pp. 352). Astana: Yelorda.

Nurmuratov, S. E. (2005). The Value Advantages of Kazakhstani Immigrants at the Present Stage. Otan tarihy, 8: 156.

Nysanbayev, A. (2005). The Kazakh diaspora in the system of Eurasian integration. The Kazakh diaspora: the present and the future (pp. 352). Astana: Yelorda.

Parsons, T. (2002). On the structure of social action (pp. 800). M.: Academic project.
Primoratz, I. (2017). Patriotism: Worldly and ethical. In Identity, self-determination and secession (pp. 91-106). Routledge.

Promotion of the socio-economic integration of oralmans. 2011. UNDP/UNV Project. Semey.

Repina, L. P. (2011). Historical science on boundary of the XX-XXI centuries: social theories and historiographical practice. Moscow: Krug Publ.

Sadovskaya, E. Y. (2007, November). Chinese migration to Kazakhstan: a Silk Road for cooperation or a thorny road of prejudice? In China \& Eurasia Forum Quarterly, 5 (4).

Sadyrova, M., S. Amitov. (2017). Migration processes in Kazakhstan and social adaptation of oralmans. Sociological analysis. Liters.

Saveliyeva, I. M., A. V. Poletayev. (2006). Knowledge of the past: theory and history: In $2 \mathrm{v}$. V.1: Construction of the past (pp. 751). St.Petersburg, Nauka.

Study of the status of oralmans in Kazakhstan (pp. 33). 2006. Almaty.

Tahir, R. (2018). Expanding horizons and expatriate adjustment: Perceptions of Western expatriate managers in multinational companies in the United Arab Emirates. Cross Cultural and Strategic Management, 25(3): 401-422.

Tanova, C., O. Ajayi. (2016). International faculty member sociocultural adjustment and intention to stay. Evidence from North Cyprus. Asian Academy of Management Journal, 21(1): 47-72.

Taušová, J., M. Bender, R. Dimitrova, F. van de Vijver. (2019). The role of perceived cultural distance, personal growth initiative, language proficiencies, and tridimensional acculturation orientations for psychological adjustment among international students. International Journal of Intercultural Relations, 69: 11-23. 